\title{
FALACIA NATURALISTA E NATURALISMO MORAL: DO É AO DEVE MEDIANTE O QUERO
}

\author{
Adriano Naves de Brito ${ }^{l}$ \\ brito@unisinos.br
}

RESUMO O objetivo deste texto é discutir alguns argumentos contra a aceitação da falácia naturalista. Pretende-se mostrar aspectos que parecem corretos na argumentação dos que recusam aquela falácia, e, a despeito de seus acertos, demonstrar que estão fundamentalmente errados. O eixo para este desfecho é a reformulação da falácia em termos da recusa da implicação entre o ser e o querer. Espera-se, assim, tornar mais claras as relações -e a ausência delas - entre verdade e moral, bem como abrir espaço para a defesa de um naturalismo moral não comprometido com a existência de fatos morais. Este texto está dividido em cinco partes. Na primeira, apresenta-se a falácia naturalista de acordo com Moore; na segunda, distingue-se essa entre as formulações de Moore e de Hume; na terceira, apresentam-se objeções à interdição da passagem do "é" ao "deve" e se formulam respostas a essas objeções; na quarta, reapresenta-se o problema da interdição entre "é" $e$ "deve" e se focaliza uma solução alternativa a ele mediante o querer; e, finalmente, na quinta parte, elaboram-se algumas conclusões acerca do naturalismo e do realismo na moral.

Palavras-chave Falácia naturalista, Naturalismo moral, Realismo moral, Controvérsia é-deve

ABSTRACT This article aims to discuss some arguments against the acceptance of the naturalistic fallacy. It intends to demonstrate that some 
aspects, which seem to be correct in the argumentation of those who refuse that fallacy, are, despite their pertinence in some points, fundamentally imprecise. In order to reach this outcome, the fallacy is reformulated in terms of the refuse of the implication between "being" and "the will". Therefore, it pretends to clarify the relations - and their absence - between truth and morality as well as enable a defense of a moral naturalism disengaged from the existence of moral facts. This text is divided in five parts. In the first one, I show the naturalistic fallacy according to Moore; in the second part, a distinction between Moore's and Hume's formulations of the naturalistic fallacy is elaborated; in the third part, I do not just present some objections to the interdiction of the passage from "is" to "ought", but also formulate some responses to them; in the forth part, the interdiction problem between "is and "ought" is retrieved and an alternative solution via the will is suggested for it; finally, in the fifth part, some conclusions are drawn about moral naturalism and moral realism.

Keywords Naturalistic fallacy, Moral naturalism, Moral realism, "Isought" problem

\section{Introdução}

A falácia naturalista, segundo a formulou Hume (1738-40), apresenta a demonstração, por redução, ao absurdo da pretensão de concluir juízos de valor a partir de juízos fácticos. Em termos gerais, a conclusão é a seguinte: do ser não se segue nenhum dever. Moore (1903), em seu Principia Ethica, explora a separação entre os planos do dever e do ser e, mediante o auxílio da análise da linguagem, pretendeu ter finalmente resolvido os mais importantes problemas éticos. Embora a distinção entre juízos constatativos e juízos morais seja amplamente aceita, e isso, sem dúvida, se deve à força da analítica da linguagem como método em filosofia, a interdição da implicação entre premissas factuais e uma conclusão normativa têm sido frequentemente questionada pelos defensores do tipo de naturalismo moral que advoga haver fatos morais. Afinal, em que sentido, se algum houver, as pretensões de verdade de juízos sobre o mundo objetivo podem se converter em pretensões de justificação de juízos morais?

$\mathrm{O}$ que se objetiva com este texto é discutir alguns argumentos contra a aceitação da falácia naturalista. Pretende-se mostrar aspectos que parecem corretos na argumentação dos que recusam aquela falácia, e, a despeito de seus acertos, tentar mostrar que estão fundamentalmente errados. O eixo para 
este desfecho é a reformulação da falácia em termos da recusa da implicação entre o ser e o querer. Espera-se, assim, tornar mais claras as relações - e a ausência delas - entre verdade e moral, bem como abrir espaço para a defesa de um naturalismo moral não comprometido com a existência de fatos morais.

Este texto está dividido em cinco partes. Na primeira, apresenta-se a falácia naturalista segundo Moore (1903); na segunda, distinguem-se entre as formulações de Moore (1903) e de Hume (1739-40) para a falácia naturalista; na terceira, apresentam-se objeções à interdição da passagem do "é" ao "deve" e dá-se respostas a essas objeções; na quarta, reapresenta-se o problema da interdição entre "é" e "deve" e apresenta-se uma solução alternativa a ele mediante o querer; e, finalmente, na quinta parte, elaboram-se algumas conclusões acerca do naturalismo e do realismo na moral.

\section{Moore e a falácia naturalista}

Para Moore (1903), a falácia naturalista consiste no procedimento de se tomar bom, o adjetivo, como sendo definido em frases como: "O prazer e a inteligência são bons”. Mais especificamente, a falácia consiste em se tentar uma definição de bom - que, a seu ver, deve ser tomado como indefinível - em termos de um objeto natural, como se bom fosse um objeto e, além disso, um objeto natural. É o que se observa em:

Mas a verdade é que um número excessivo de filósofos têm pensado que ao enumerar todas essas outras propriedades (que têm as coisas que são boas) estava de facto a definir bom, que essas propriedades não eram "outras", diferentes, mas se identificavam total e absolutamente com bondade. A esta posição propomos que se dê o nome de "falácia naturalista". (MOORE, 1903, p. 92)

Quando uma pessoa confunde dois objetos naturais, definindo um em função de outro, por exemplo, confundindo-se a si mesma, que é um objeto natural, com "sentir prazer" ou "prazer", que também o são, não há qualquer justificação para que se fale de falácia naturalista. Mas se confundir "bom", que não é, no mesmo sentido, um objeto natural, com um objeto natural, seja ele qual for, então, sim, há motivo para se dizer que é uma falácia naturalista. (MOORE, 1903, p. 95)

Como se vê, o nome falácia naturalista decorre do fato de que o que provoca o erro na argumentação é a definição de bom por um objeto natural. Toda vez que se faz isso, o resultado é um argumento que não pode ser refutado, porque é uma tautologia. Como se pode definir bom por diferentes objetos naturais, cada um desses argumentos será uma tautologia e não se poderá decidir qual das teorias em questão estará correta. A falácia naturalista interdita, nessa medida, qualquer discussão ética. 
Veja-se o exemplo que dá Moore (1903) a propósito do utilitarismo clássico. Se Bentham (1789) tivesse definido correto como as ações que levam à obtenção do que é bom, então o correto seria o que é bom como um meio para se alcançar o que é bom em si, o bem. Correto poderia, então, ser definido como "conducente à felicidade". Isso, é claro, sob a condição de que se defina, antes, que apenas a felicidade geral é o bem, ou que apenas ela é boa (o que Moore toma como sendo a mesma coisa). Se correto é conducente ao bem, e o bem é a felicidade geral, então correto é o conducente à felicidade geral.

Contudo, o que Bentham (1789) diz é que seu princípio fundamental estabelece que a felicidade de todos aqueles cujo interesse está em causa constitui o objetivo correto e próprio da atividade humana (MOORE, 1903, p. 101). Correto é, então, identificado com o objetivo em si (ele, o objetivo, é correto e não os meios para alcançá-lo). Logo, "a felicidade é o objetivo correto" deve ser lida como uma identidade (definição), isto é, como "é o mesmo que". Donde se conclui que correto não pode mais ser o "conducente à felicidade" sem que se tenha como resultado uma falácia, neste caso, um argumento circular que resulta da identificação do que é bom com um objeto natural: a felicidade geral.

A falácia está em que o argumento para se provar que a felicidade é o fim próprio da atividade humana consiste na definição de correto, e essa definição remete ao que deveria ser provado, a saber: a felicidade geral. Se correto é o mesmo que conducente à felicidade geral, então a felicidade geral é o correto (o fim correto). Eis o truísmo. Ele permite agora provar o princípio de que a felicidade geral é o bem: se correto é o conducente à felicidade geral e correto é o que é bom, então a felicidade geral é o bem (o que significa tanto quanto: se o bom é o que conduz à felicidade, então a felicidade é boa, ou é o bem, mediante a substantivação do adjetivo). A prova reside, no entanto, numa definição e, embora a conclusão possa estar correta (a felicidade geral pode mesmo ser o bem) o argumento nada prova. Basta que outro defina o correto como, por exemplo, o que conduz ao prazer, para se obter o resultado igualmente válido de que o que dá prazer é o bem. O silogismo é o seguinte: correto é o que conduz ao prazer. O correto é o que conduz ao bem. Logo, o que conduz ao prazer conduz ao bem, pois são uma e mesma coisa. É claro que correto significa o mesmo que bom e este pode substituir aquele nesta argumentação (Tem-se, pois: bom é o que conduz ao prazer. O bom conduz ao bem. Logo, o que conduz ao prazer conduz ao bem, pois são idênticos: o prazer é o bem.). O resultado, para Moore (1903), é que se deve tomar bom como indefinível, não analisável, caso contrário pode-se cair nesta falácia: a falácia naturalista. 
O juízo de que a falácia naturalista é inevitável em toda tentativa de definir bom decorre, para Moore (1903), da peculiaridade da ética com cujos juízos nenhuma redução dela ao mundo natural é compatível. Como as definições de bom (substantivado, então, em o bom, o bem), aos moldes das definições de propriedades naturais, implicam alguma identificação do conceito com objetos naturais, a falácia é inevitável. Moore (1903) propõe, como alternativa, uma peculiar intuição ética de que se é detentor e que permite acessar o bom. Assim, embora antinaturalista, Moore (1903) não é um antirrealista em ética. Esta é uma combinação não menos indigesta que a entre o naturalismo e o realismo. $\mathrm{O}$ que se pergunta é se há alguma alternativa naturalista ao realismo, quer dizer, se pode haver um naturalismo não realista.

\section{Ser e dever em Hume}

A formulação mooreana da falácia naturalista tem, diretamente, muito pouco a ver com o que se costuma chamar por este nome em filosofia prática. É comum encontrar na literatura, sob o título de falácia naturalista, o erro que se cometeria ao passar do plano do ser para o plano do dever. Moore (1903) explora a distinção entre estes dois planos, não para explicar a falácia naturalista, mas por acreditar que, de fato, a ética somente é acessível mediante uma especial intuição por estar ela em outro plano que não o do ser. Sobre isso nada mais se tem a dizer aqui. O que interessa é averiguar, agora, a estrutura dessa falácia, que também é chamada de naturalista, e que consiste em derivar um dever de premissas fáticas, porém cuja formulação não remonta à Moore (1903), mas a Hume (1739-40). O uso do nome se deve a que as mesmas doutrinas naturalistas criticadas por Moore (1903), por cometerem a falácia naturalista, também cometem essa outra. Afinal, ao identificar o bom com um objeto natural, naturalizam-se os valores e, com isso, transita-se, inadvertidamente, do ser ao dever, da natureza à moral. Para Moore (1903), não obstante essa convicção, a posse de uma intuição ética especial permitiria discernir também em ética o verdadeiro do falso, mesmo que esses habitassem outro plano que o plano natural. Nesse ponto, há uma irremediável diferença entre a sua concepção e a de Hume (1739-40).

A passagem clássica em que Hume (1739-40) apresenta o que ficou também conhecido como o problema do "é-deve" (is-ought) é a seguinte:

Em todo sistema de moral que até hoje encontrei, sempre notei que o autor segue durante algum tempo o modo comum de raciocinar, estabelecendo a existência de Deus ou fazendo observações a respeito dos assuntos humanas, quando, de repente, surpreendo-me ao ver que, em vez das cópulas proposicionais usuais, como é e não é, 
não encontro uma só proposição que não esteja conectada a outra por um deve ou não deve. Essa mudança é imperceptível, porém da maior importância. Pois como esse deve ou não deve expressa uma nova relação ou afirmação, esta precisaria ser notada e explicada; ao mesmo tempo, seria preciso que se desse uma razão para algo que parece inteiramente inconcebível, ou seja, como essa nova relação pode ser deduzida de outras inteiramente diferentes. (HUME, 1739-40, §27 do L. II, Parte I, Seção I)

Hume (1739-40) aponta que a dedução de deveres a partir de premissas formuladas com elementos factuais não é válida e isso está de acordo com sua tese fundamental de que as distinções morais não são percebidas pela razão e não são distinções de objetos. Ora, por essa razão, juízos morais não podem ser verdadeiros ou falsos, no sentido lógico usual desses termos. Na verdade, eles não são juízos descritivos, mas avaliativos. Sobre essa tese, pesa uma controvérsia a ser referida brevemente na sequência desta exposição.

\section{Objeções à invalidade da dedução do "deve" do "é"}

Suponha-se o seguinte argumento: não se deve impedir a prática religiosa das minorias, pois a religião é uma questão de estrita escolha pessoal. $O$ que Hume (1739-40) teria colocado em dúvida é a validade da derivação do dever expresso no argumento do fato de a religião ser uma questão de escolha pessoal. $\mathrm{O}$ argumento estaria em ordem, se construído um silogismo prático como segue:

P. maior: Nada do que é uma questão de estrita escolha pessoal deve ser proibido.

P. menor: Religião é uma questão de estrita escolha pessoal.

Conclusão: A religião não deve ser proibida.

Nesse silogismo, o dever expresso na conclusão foi derivado do dever expresso na premissa maior. Alguns autores, em número cada vez mais expressivo, recusam esta interdição. Analisam-se três desses argumentos.

\section{1 MacIntyre}

MacIntyre (1969), em seu artigo intitulado Hume on "is" and "ought", propõe que, naquela clássica passagem (citada acima), Hume (1739-40) não teria a intenção de afirmar que há um intransponível abismo entre "é" e "deve". $\mathrm{Na}$ linha dessa interpretação, MacIntyre (1969) explica o "deve" em termos do "é" do seguinte modo: "O 'deve' - afirma ele - é logicamente dependente de um conceito de um interesse comum e somente pode ser explicado nos termos desse conceito" (MACINTYRE, 1969, p. 41). Assim, que alguma coisa deva ser feita, depende de que haja um consenso dominante sobre o 
interesse comum do que deve ser feito. Em outros termos: do fato de que X seja o que é do interesse geral que seja feito (é o que os homens querem ou precisam que seja feito), segue-se que $\mathrm{X}$ deva ser feito.

Ao que parece, a derivação de MacIntyre (1969) falha. Se não, veja-se. O que é do interesse comum é o que todos querem (ou pelo menos a maioria dominante), mas do fato de que todos queiram $X$, ou seja, da verdade da frase 1. "Todos querem X", não se segue que todos devam fazer X. Segue-se apenas que, de fato, todos querem. O dever não resulta da constatação da vontade de todos. Não resulta porque, com o dever, se introduz uma obrigação, isto é, a necessidade de que algo seja feito, mesmo que não seja isso o que os envolvidos queiram. O dever envolve um elemento normativo que não aparece na frase constatativa sobre a vontade geral.

Deve-se compreender bem o alcance da filosofia moral de Hume. O que ele se esforça por mostrar é que o ser age motivado por interesses e desejos e não por princípios ou distinções racionais. Entre o que é vício e o que é virtude (ou entre o que é bom e o que é ruim) não pode distinguir a razão. Mas essa psicologia da moral (quer dizer: a explicação psicológica do fenômeno moral) não é, ainda e por si só, suficiente para explicar a pretensão de validade intersubjetiva dos juízos morais. O que se pode perguntar aqui é: o que há no "deve" que ainda não está no "quero"?

\section{2 Zimmerman}

Uma outra proposta para cobrir o vão que separa "é" e "deve", é a feita por Zimmerman (1962) em seu The 'is-ought': an unnecessary dualism, é a conversão, e consequente possibilidade de eliminação, de todas as frases com "deve" em frase com "é". Assim, tudo o que se pode dizer com "deve", se deveria poder dizer com "é". A ideia fundamental é que não se pode dar para frases com "deve" mais justificativas do que se dão para frases com "quero". Logo, toda frase que envolve uma obrigação, mais não seria do que uma frase sobre um desejo de que algo fosse feito. Contudo, parece evidente que há uma diferença semântica relevante entre expressar o que é de fato o desejo e expressar um dever, mesmo que seu fundamento seja apenas o um desejo. Se se diz a alguém: 2. "Você deve fazer X", não se está - pelo menos não apenas isso - a comunicar ao interlocutor que, nesse momento, se tenha um desejo específico, mas se afirma que ele deve fazer o que a ele se diz, seja isso de sua vontade ou não, e seja isso da vontade de quem lhe expressa o dever, ou não. Coloca-se este que diz a frase 2 na sentença normativa na posição de um sujeito geral. Não é nem a vontade do concernido, nem a daquele que pronuncia a frase que estão em jogo. Esse é o sentido da obrigação. A 
conversão de sentenças com "devo" em sentenças fáticas, ou deixa de fora um elemento semântico fundamental, o sentido da obrigação, ou apenas repõe o problema da distinção entre juízos descritivos e normativos para uma outra formulação.

\section{III.3 Searle}

A última proposta para justificar a derivação do "deve" para o "é" que se deseja analisar é a que faz Searle (1962). Em seu artigo How to derive 'ought' from 'is', Searle (1962) dá o seguinte exemplo de como fazer a derivação em vista:

1. João enuncia as palavras: "prometo aqui pagar a você, Silva, cinco reais".

2. João prometeu pagar cinco reais a Silva.

3. João colocou-se a si mesmo sob a obrigação de pagar a Silva cinco reais.

4. João está sob a obrigação de pagar a Silva cinco reais.

5. João deve pagar a Silva cinco reais.

Ora, do fato enunciado na frase 1 não se segue, sem mais, que haja uma obrigação entre João e Silva. Justamente a obrigação não é um fato como o é o enunciar uma frase. O prometer, no entanto, não encontra o seu pleno sentido, senão por seu aspecto normativo, que envolve a obrigação selada entre os contratantes. E uma vez introduzida a noção de obrigação nas premissas, é claro que já se pode concluir o dever de João para com Silva, pois esse dever é agora a expressão da obrigação antes postulada. O ponto de Searle (1962) é que as assunções em 1, 2, 3 e 4, não têm caráter avaliativo (ou normativo), mas são meramente descritivas. Novamente, parece evidente que há uma relevante diferença entre descrever que João enunciou uma frase a Silva, e descrever que João prometeu algo a ele de modo que o prometido passa a constituise numa obrigação para João. Do ponto de vista meramente descritivo, que uma sentença tenha sido enunciada depende de que um fato tenha ocorrido: a locução de uma frase. Que uma promessa tenha sido feita, depende de que João esteja disposto a aceitar uma norma: cumprir o que foi prometido. Para uma obrigação, não é suficiente que uma frase seja enunciada, é preciso que esteja vigente entre as partes um acordo moral; ou, ainda, é necessário que a frase seja asserida com a atitude proposicional correspondente. No caso em questão, a cobrança de uma obrigação moral assumida por João, ao fazer uma promessa para Silva. É essencial, para esse acordo, que o prometido seja cumprido (ou, pelo menos, que se faça de boa fé todo o esforço para isso, dentro, obviamente, das possibilidades fáticas disponíveis) a despeito dos desejos e interesses dos envolvidos. Ora, as frases de 1 a 4 não são meramente descritivas. Já em 1, a promessa traz para o contexto o normativo. $\mathrm{O}$ argumento funciona porque já, 
desde o início, o normativo está presente. O problema é ainda a natureza desse normativo. De onde ele tira a sua força? Se não a obtém da mera enunciação, então é da intenção do enunciador. A questão retorna mais uma vez: o que há no "deve" que ainda não está no "quero", na intenção de João?

\section{Como se vai do "quero fático" ao "quero moral"?}

Todas as sugestões discutidas introduzem, em algum momento, o querer como fundamento do dever. Por razões que, em virtude dos limites desta exposição, não é possível expor, há a tendência de pensar que, se algum fundamento se puder dar para a moral (e ela não poderia vigir entre os homens se fosse completamente infundada), então ele tem mesmo de ser o querer. Não obstante essa concordância quanto à fundamentação da moral, há entre o que pensa o articulista e os três autores comentados uma diferença decisiva. A diferença é a mesma que separa, de maneira irreconciliável, o pensamento moral de Moore (1903) e Hume (1739-40), a saber: para o primeiro, juízos morais podem ter um valor de verdade e, para o segundo, não. À diferença dos autores aqui discutidos, não se considera que juízos morais sejam equivalentes ou mesmo redutíveis a juízos fáticos, mas se aposta na rigorosa distinção entre os planos do ser e do dever. Pois bem, se o querer é o fundamento da moralidade, como tendo a conceder, e o querer é algo sabidamente fático, como pode ele fundar algo que está para além do descritível?

A seguir, esquematiza-se esta passagem com um silogismo prático:

A. Se a ação X me agrada, então ela deve ser feita.

Tomando o dever como fundado num querer, posso parafrasear essa frase com a frase "B".

B. Se a ação X me agrada, então eu quero que seja feita.

Supondo agora a premissa "C":

C. A ação X me agrada.

Terei, então:

D. Eu quero que a ação X seja feita. 
Como, agora, a partir disso, que é um silogismo prático de caráter naturalista, introduzir o dever? Como sair de "D" para "E"?:

\section{E. A ação X deve ser feita.}

É possível entender essas passagens analisando o dever em termos do querer. Essa seria uma leitura naturalizada. Ora, o "deve" implica em "E" tanto quanto implica em "F".

F. Eu quero que a ação X seja feita sob quaisquer circunstâncias das vontades dos envolvidos, inclusive a minha própria.

As circunstâncias naturais eventualmente impeditivas da ocorrência de $\mathrm{X}$ não precisam ser mencionadas, já que é tolice querer algo naturalmente impossível e o que não ocorre por impossibilidade natural não é passível de julgamento moral. Assim, "F" pode ser analisado do seguinte modo:

G. Eu quero que todos queiram que a ação X seja feita.

Pois bem, o que está no deve que ainda não está no querer subjetivo é o querer que o que se quer seja o que todos queiram. ${ }^{2}$ É esse querer, e somente ele, que tem um caráter moral. É isso o que fica explícito na análise $e^{3}$ de "E" em "F" e "G". A moralidade está constituída por quereres que se querem dominantes. Em consonância com isso, o dever é o querer que se quer dominante, um querer que quer ser o querer de outras vontades (e mesmo o da minha, se ela tender a mudar de direção). É esse querer dirigido aos demais, mas também reflexivo, portanto, a todos concernente, que é desse modo objetivado. É ele que permite a passagem do plano no fático subjetivo (eu quero, eu desejo) para o plano do normativo (eu quero que todos queiram, deve-se!). A descrição meramente fática do querer não dá conta do compromisso do querer moral com a vontade dos concernidos, a que, precisamente, dirige-se o querer normativo.

Mesmo que a expressão de uma disposição volitiva subjetiva seja, em princípio, a expressão de algo fático, o desejo subjetivo, o que transcende a faticidade subjetiva desse querer (presente) é que ele se projeta para um plano

2 Confrontar, a propósito, a teoria moral de Tugendhat, em especial, Lições sobre ética, 1993, e o artigo Como devemos entender a moral, 2001.

3 Vale ressaltar que o silogismo terminou em "D". "E", "F" e "G" não são conclusões adicionais, mas análises de "E". Portanto, uma análise naturalizada de como o quero em "D" deve ser entendido no âmbito da moralidade. 
geral, não mais fático, porque não constatável imediatamente, mas normativo. Um plano no qual as vontades da comunidade moral (a vontade de cada eu concernido) exercem pressões mútuas para que as coisas se passem (no futuro) como o devido. A mediação entre o ser e o dever é feita pelo querer, mas um tipo específico de querer, o querer moral, dirigido, portanto, ao querer de todos os demais.

A postulação deste plano geral no qual a vontade se coloca e partir do qual legisla praticamente encontra equivalência nos enunciados assertivos. Ao fazer uma asserção descritiva sobre o mundo, o falante toma distância de suas próprias representações e se projeta para um plano geral. Muito embora o sujeito disponha sempre e apenas de suas representações, sem o movimento de tomar distância delas, seu discurso perderia o valor cognitivo, deixaria de candidatar-se a um valor de verdade. De modo análogo, não obstante tenha o sujeito prático apenas os seus desejos, o seu querer fático, sem tomar dele distância, sua legislação perderia o valor, pois deixaria de candidatar-se à avaliação pública que a distinguiria como boa ou má. O querer despretensioso com respeito aos demais quereres, como o estético, por exemplo, não está submetido ao crivo da avaliação moral.

\section{Conclusões}

E o que dizer do naturalismo sem realismo? Pelas reflexões feitas até aqui é evidente que concordo com a ideia geral de que a moral tem de estar inserida no mundo natural e a via de ligação entre ambos, moral e natureza, é o querer dos agentes (querer que é, por suposto, determinado pelos interesses subjetivos a que cada um está exposto como ser natural). É nesses termos que defendo o naturalismo na moral. Quanto ao realismo, a ele está vinculada a ideia de que às distinções morais - bem, mal, bom e mau - correspondem fatos. $\mathrm{O}$ naturalismo aliado ao realismo apresenta um mundo em que há fatos morais. Isso vai muito além da afirmação de que os fatos morais estão vinculados ao mundo (pelo querer, por exemplo). O realista no tocante à moralidade aceita que os valores morais podem ser identificados (e até percebidos) no mundo como o são outras propriedades naturais. Disso, discordo. A naturalização da moral não implica, necessariamente, na redução do valor ao mundo fático. A comparação entre valor moral e valor cognitivo sugerida acima mostra que nem mesmo a verdade ou falsidade podem ser assim reduzidas. O ponto fica mais evidente quando se pergunta pelos critérios de validade dos valores atribuídos aos enunciados que se proferem, sejam eles práticos ou teóricos. A procura por alguma correspondência entre eles e suas contrapartidas naturais não resolve 
a dificuldade. É claro que caso se encontrasse o que lhes correspondesse, terse-ia de perguntar, mais uma vez, pelo critério de correspondência entre o que se encontra e aqueles valores. Nesse sentido, eles são, de fato, como apontava Moore (1903), indefiníveis.

Não posso, aqui, ir além desse ponto. O próximo passo é procurar compreender melhor a natureza do plano em que vigem os valores. $\mathrm{O}$ peculiar desse plano é sua sui generis natureza entre imbricado na natureza e, no entanto, não redutível a ela. Face a essa constatação sobre o caráter bidimensional dos valores natureza, parece-me que uma via de acesso a eles se abre. Refiro-me à investigação da natureza do significado que, como os valores, se encontra naquela mesma peculiar posição: no mundo e, contudo, fora dele.

\section{Referências}

BENTHAM, J. (1789). Uma introdução aos princípios da moral e da legislação. São Paulo: Abril Cultural, 1979.

HUDSON, W. D. (Org.). The is-ought question. Bristol: Macmillan, 1969.

HUME, D. (1739-40). Tratado da natureza humana. São Paulo: Unesp, 2000.

MACINTYRE, A. (1969). Hume on "is" and "ought”. In: HUDSON, W. D. (Org.). The is-ought question. Bristol, Macmillan, 1969.

MOORE, G. (1903). Principia Ethica. Lisboa, Calouste Gulbenkian, 1993.

SEARLE, J. (1969). How to derive 'ought' from 'is'. In: HUDSON, W. D. (Org.). The is-ought question. Bristol: Macmillan, 1969.

TUGENDHAT, E. (1993). Lições sobre ética. Petrópolis, Vozes, 1997.

TUGENDHAT, E. (2001). Como devemos entender a moral. Philósophos, v. 6, n. 1-2, p. 59-84, 2001.

ZIMMERMAN. M. (1962). The 'is-ought': an unnecessary dualism. Mind, 1962, v. 71, n. 281, p. 53-61. 